\title{
Previous experiences of University new entrants' school library usage: with reference to veterinary medical students, University of Peradeniya, Sri Lanka
}

S. Weerasinghe ${ }^{1}$

\begin{abstract}
This study attempted to examine the prior school library experiences of new entrants in the field of Veterinary Medicine and Animal Science and their pattern of information source usage. Data were gathered by performing a questionnaire-based survey among the study population $(\mathrm{N}=71)$ of all the new entrants to the Faculty of Veterinary Medicine and Animal Science in 2020.The findings revealed that $93 \%$ of the students have been instructed by school teachers to refer additional reading material to complement classroom notes and almost all the students confirmed that they utilized the school library while studying for their GCE A/L exam. It was observed that $73 \%$ of the students had visited the school library once a week or few days a week. Regarding the availability of library facilities all the students stated that they had facilities to borrow books while $47 \%$ of them had facilities to borrow magazines too. Yet, only $32 \%$ of students reported that library catalogs were available in their school libraries. In addition, $90 \%$ of the respondents did not have computers as well as internet access in the school library. Findings further demonstrated that most of the students (98\%) had borrowed books from the school library while only few students $(13 \%)$ had used the catalog for information retrieval. It was interesting to note that $95 \%$ of the students perceived the need to refer additional material to complement their classroom notes. $95 \%$ of the respondents confirmed that other than the school library they gained subject-related material from tuition classes. Inevitably, all the respondents verified that they had an email account and $97 \%$ of them stated that they used social media. Moreover, $93 \%$ of students ascertained
\end{abstract}

${ }^{1}$ Senior Assistant Librarian, Library, University of Peradeniya, Sri Lanka

Email: sureniw1@yahoo.com (D): https://orcid.org/0000-0001-7337-8408 
that they preferred to communicate with the library via digital media. This paper renders insight into the adequacy of prior school library usage by university new entrants which can be used as a baseline indicator in designing and planning library instructional programs for students. Library instructional programs could be planned to have more focus on areas (eg. Online catalogs, e-resources) that were revealed to be less experienced by the students.

Keywords: University, New Entrants, School Library, Sri Lanka, Veterinary, Undergraduates 


\section{Introduction}

University libraries are an inextricable component in the higher education sector and serve as the focal point for delivering standard information to the learning, teaching and research communities. According to Alade, Iyoro and Amusa (2014), libraries appear as "the powerhouse for academic activities by carefully selecting, processing and storing relevant information that could be retrieved to meet both academic and leisure demands of all members of the university community".

On the other hand, school library is a part of the school in which book collections, periodicals, magazines, newspapers, computers, videos etc. are housed for utilization by students and teachers (Fayose, 1995). The various information resources available in the school library will fulfill information needs of school education programs while enhancing the reading skills and learning patterns of students (Benard \& Dulle, 2014). The degree of creativity and knowledge-ability of young students will be shaped by their school library resources usage. (Salisu, 1996, as cited in Benard \& Dulle, 2014). Moreover, the school library enables teachers and students to be in par with new developments by rendering up-to date information that supports the curriculum (Fakomogbon, Bada, Omiola \& Awoyemi, 2012).

Undergraduates are the main user category of university libraries and it's highly important that the library management be aware of the information behaviors of their users in order to render effective services.It is important to reorient library services and resources in order to satisfy user needs. Every year new students enter the university and they possess diverse needs, expectations and different levels of knowledge as well as information gathering skills. Some may possess experience in using their school library while some others may not. Besides, Bransford, Brown and Cocking (2000) outline that, students "come to formal education with a range of prior knowledge, skills, beliefs and concepts that significantly influence what they notice about the environment and how they organize and interpret it".

There is a common perception among the university system that undergraduates have adequate skills to use the university library and do not require special guidance and training on library usage (Wijetunge \& 
Gunasekera, 2015; Wijetunge, 2018). Yet, university libraries consist of advanced information systems in comparison to school libraries. Thus, retrieving, locating, accessing information mainly via digital media with diverse platforms have become a complex task. Kassim (2017) ascertains that "new technologies, databases, and more innovative systems for accessing information, have made the library more complicated and challenging for users". It is important that students are equipped with necessary library skills for the advancement of their knowledge base and successful completion of their academic work. Understanding prior library experiences of incoming students will enable librarians to identify gaps in information skills and competencies of students and play a crucial role by supporting the students to develop strategies for information retrieval. This will in turn enhance the students' skills of critical thinking to engage successfully with scholarly information in this complex information environment. Nevertheless, it is imperative that university libraries be in par with technological advancements by introducing innovative services to better serve the tech-savvy young users.

The current study was conducted in order to obtain a better understanding about the previous school library usage of new entrants and to investigate the pattern of their information source usage. A survey was performed among new entrants to the Faculty of Veterinary Medicine and Animal Science, University of Peradeniya, Sri Lanka.This survey will aid the library management to understand the level of prior library usage of students and in turn help to satisfy user information needs productively. Library instructional programs, orientation programs and effective services could be designed in accordance with the findings of this study.

\section{Research Objectives}

The overall objective of this study is to evaluate the prior library experiences and information sources utilized by the new entrants to the Faculty of Veterinary Medicine and Animal Science in order to evaluate whether they have adequate experience in school library usage. 
The specific research objectives of the study are as follows:

1. To study previous experiences of new entrants in using school library spanning the frequency of library visits, availability and use of library facilities and services

2. To determine the information sources used by them

3. To inquire their social media use

4. To study their internet and email usage

5. To investigate their preference to communicate with the library via digital media

\section{Literature Review}

The literature revealed a considerable number of studies that have been engaged in examining university undergraduates' academic library usage. However, research that focus on university new entrants' prior school library usage is scarce in the literature.

Alade et al. (2012) applied the questionnaire-based survey strategy to study the library use characteristics of university undergraduates in a Nigerian University.The study population comprised all the undergraduates $(\mathrm{N}=426)$ of the university with no special focus on new entrants. Yet, one of the specific objectives of the study was to determine the association between use of school library and use of university library by the students. Findings revealed that students' prior knowledge of school library use significantly influenced their use of the university library. In addition, library instruction programs also had a positive impact on the library use. Furthermore, it was found that the respondents used the university library few days per week only to satisfy their academic purposes (Alade et al.,2012). In a related study, Whitmire (2001) conducted a longitudinal study to investigate factors influencing undergraduates to use the academic library during the first three years of college. In this study, high school library use was identified as a key determinant of undergraduates' library use during all three years of the study. Results indicated the significance of encouraging undergraduates to develop their library skills during school education (Whitmire, 2001). In addition, student-faculty interactions, active learning and engaged writing activities were strong predictors of library use. The authors concluded that the study 
results would aid in redesigning the current academic library services (Whitmire, 2001).

In a different study, Ukpebor and Emojorho (2012) examined the entry-level Information Literacy (IL) skills of first year students of University of Benin. Data were gathered via surveying 1000 students from five faculties who were selected based on simple randomization. Findings demonstrated that the students had not been educated about IL skills at secondary school and that they possessed little knowledge on IL skills. Also, it was found that the students had insufficient understanding with regard to search strategies, mainly about using the Boolean operator. The author highly recommended that IL programs should be integrated in the school curriculum while guiding the students towards optimal utilization of the school library (Ukepebor \& Emojorho, 2012). In another study, Hartmann (2001) conducted focus group interviews among first year undergraduates at University of Ballarat in order to investigate the perceptions of the students towards IL. In conclusion, the author stressed the importance of addressing the issue of "lack of transference of skills from secondary school libraries to the tertiary library setting" (Hartmann, 2001).

In the Sri Lankan context, only a few studies that explored prior library experiences of university new entrants have been reported.

Wijetunge and Gunasekera (2015) carried out a questionnaire-based survey to identify prior experiences of library use by Management new entrants of University of Peradeniya in 2015. Findings exhibited that school teachers had instructed all the respondents to read material in addition to their class room notes. Also, more than $85 \%$ of participants had used their school library during GCE/AL exam. Most of them had visited the school library once a week mainly to borrow books. Less than half of students had used a catalog for locating information while majority of them had not used computers in the school library. In addition, it was revealed that more than half of the respondents had email and social media accounts and that they preferred to communicate with the library via these digital platforms. The authors concluded that library training programs for new entrants could be designed in accordance with the study results (Wijetunge \& Gunasekera, 2015). Along similar lines with the study of Ukpebor and Emojorho (2012), 
Gunasekera (2018) sought to analyze the entry-level Information Literacy (IL) skills of first year students via surveying Management freshmen of University of Peradeniya in 2017. This survey revealed interesting results about the prior school library experiences of the new entrants. It was observed that more than half of the students had been instructed by their school teachers to read subject-related material in addition to notes in class. Even though most of the students had not attended any IL course in school $78 \%$ of them reported that they had used the school library mainly for the purpose of book borrowing. Results further revealed that majority of the students had not used a catalog for information retrieval. On the other hand, most of the new entrants confirmed that they had prior experiences in using computers and Internet. The author outlined the importance of designing effective IL programs for university freshmen (Gunasekera, 2018).

In another study, Kumara (2014) investigated level of Information and Communication Technologies (ICTs) by new entrants of University of Moratuwa. Data collection was done via a questionnaire distributed among 338 freshmen. Findings demonstrated that the first year students as digital natives were rapidly inclined towards high ICT usage (Kumara, 2014). It was revealed that majority of respondents perceived themselves as highly skilled in using computer applications. Regarding ICT usage and computer literacy skills male students surpassed female students. In addition, most of the new students believed that ICTs were helpful to enhance their learning. The results of the study would aid in developing existing programs and implementing new programs effectively for new students (Kumara, 2014).In an attempt to explore characteristics and information seeking behavior of students, Mashroofa (2012) also used new comers from three Sri Lankan universities as research subjects. Data were collected via a survey and analyzed using qualitative as well as quantitative methods. It was revealed that most of the respondents used the internet but library web pages and online catalogs were seldom used by them. Also, majority of students stated that they were comfortable in directly communicating with the librarian while some of them preferred to communicate with the library using email, Facebook and instant messaging. The author recommended that IL programs should be delivered as a course module (Mashroofa, 2012). Yet, this study did not provide any insights into the prior school library usage of the university freshmen. 
The literature amply demonstrates evidence in support of undergraduates' academic library usage across various contexts. However, there is a dearth of studies that have been focused on exploring prior school library use of university new entrants and in the context of Sri Lanka very few studies have attempted to address this issue. Moreover, literature on examining prior library experience of students in the Veterinary Medical discipline is scarce. The current study will contribute to fill this gap in the LIS literature.

\section{Methodology}

The survey research strategy was employed in this study. The study population was all the students ( $\mathrm{n}=71)$ who entered the Faculty of Veterinary Medicine and Animal Science (FVMAS) in 2020. Sampling techniques were not employed since the entire study population was taken into consideration in this study. A self-designed, structured questionnaire was the main research tool for data collection and it was administered to all new entrants of the FVMAS at the point of library registration during the first week of January 2020. 59 duly filled usable responses were returned rendering a response rate of $83.1 \%$. The responses received were recorded and tabulated in alignment with the research objectives using Statistical Package for Social Sciences (SPSS) (version 23) and data analysis was done using descriptive statistics.

\section{Results and Discussion}

The results from descriptive statistics related to the students' gender indicated that majority of students $(67.8 \%)$ who participated in the survey were female whereas $32.3 \%$ of them were male respondents (Figure 1).

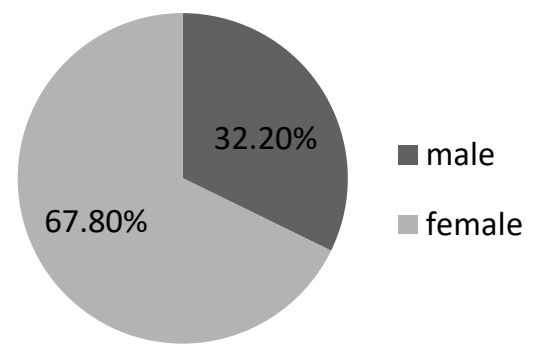

Figure 01. Distribution of the respondents by gender 
Majority of the respondents (93.22\%) reported that they have been instructed by their school teachers to refer subject-related materials in addition to classroom notes. This result is in conformity with results obtained by Wijetunge and Gunasekera (2015) and Gunasekera (2018). It is important that school teachers encourage students to use the library in order to find information to consolidate their classroom notes, which in turn will pave the way for students to participate in active learning, facilitating the process of knowledge construction. Almost all of the participants (96.61\%) except a few $(3.39 \%)$ asserted that they utilized the school library while studying for their GCE Advance level examination which is a positive trend towards library usage. Similar results were found in prior studies (Wijetunge \& Gunasekera, 2015; Gunasekera, 2018) that were focused on studying library experiences of new comers of the Management discipline.

\section{Frequency of Library Visits}

The frequency of library visits is a significant tool of measurement for library usage. With regard to the frequency of library visits by the survey respondents, it was observed that most of the students $(47.46 \%)$ had visited their school library once a week, $25.42 \%$ visited the library few days a week and $13.56 \%$ visited the library once in two weeks (Figure 2). Yet, there were some students $(8.47 \%)$ who had rarely visited their school library (Figure 2).

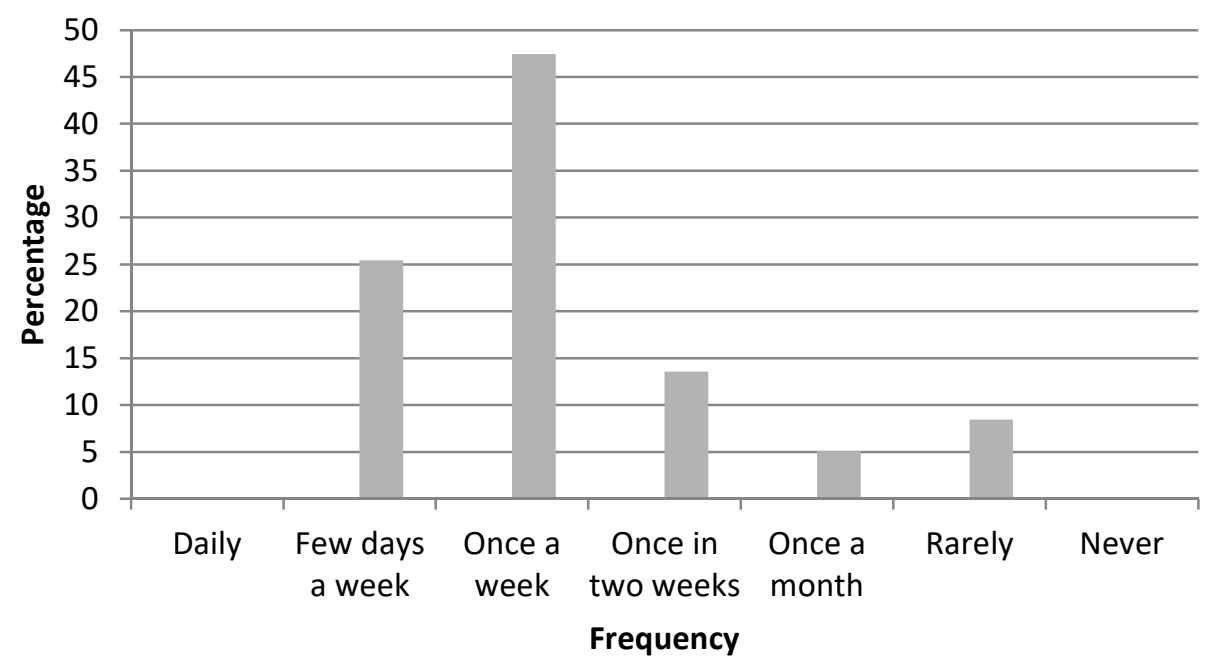

Figure 02. Frequency of library visits 


\section{Availability of Library Facilities and Services}

The survey participants were inquired about the library facilities and services available in their school libraries. Figure 3 illustrates the results. It was revealed that all of the students had book borrowing facilities while a substantial proportion of them $(47.46 \%)$ had magazine borrowing facilities in the school library (Figure 3). Regarding library catalogues, $32.20 \%$ mentioned that a library catalog was available in the school library. However, most of the students $(89.83 \%)$ did not have computers nor did majority of them $(93.22 \%)$ have access to Internet/WiFi in their school libraries.

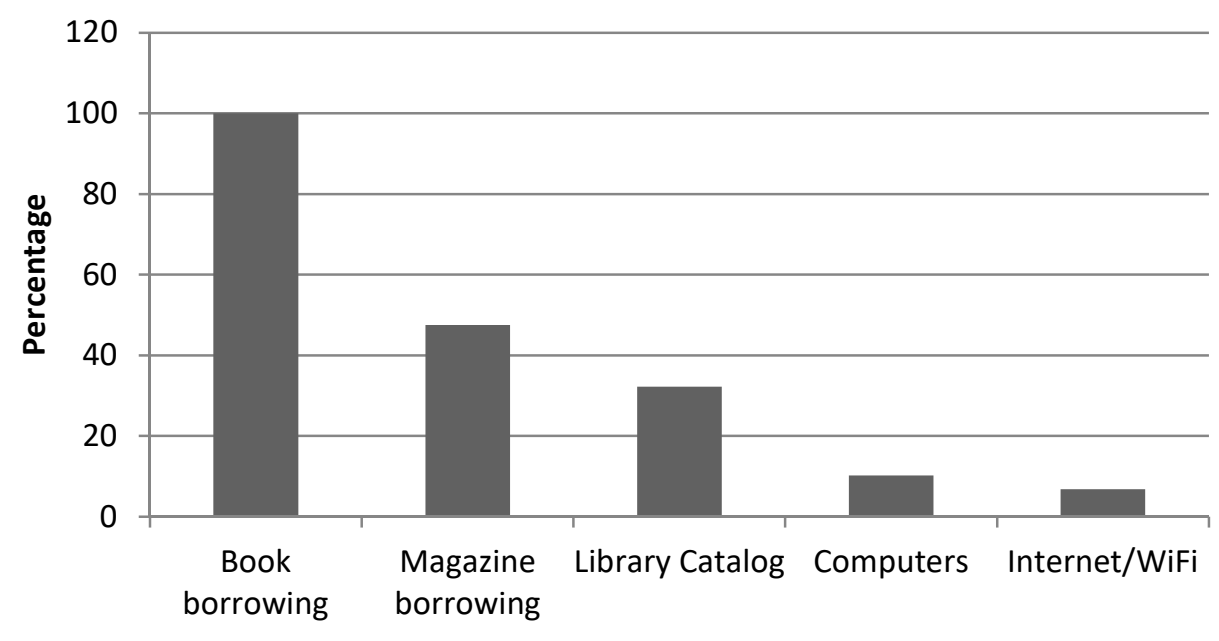

Library facilities and services

\section{Figure 03. Availability of school library facilities and services}

\section{Use of Library Facilities and Services}

Figure 4 demonstrates the use of facilities and services in the school library by the respondents. According to the findings almost all of the respondents (98.3\%) had borrowed books while some of them $(28.81 \%)$ had also borrowed magazines (Figure 4). Only few students (13.56\%) had used the library catalog to retrieve information. This result indicates that the new entrants may be less familiar in using the computerized library catalog. Furthermore, majority (96.61\%) of the respondents had not used computers as well as Internet/Wifi facilities in the school library which points out that most of the students may not have exploited computers and internet for academic purposes. In the same way, Wijetunge and Gunasekera (2015) 
observed that a high percentage of freshmen of Management discipline also had not utilized computers in the school library.

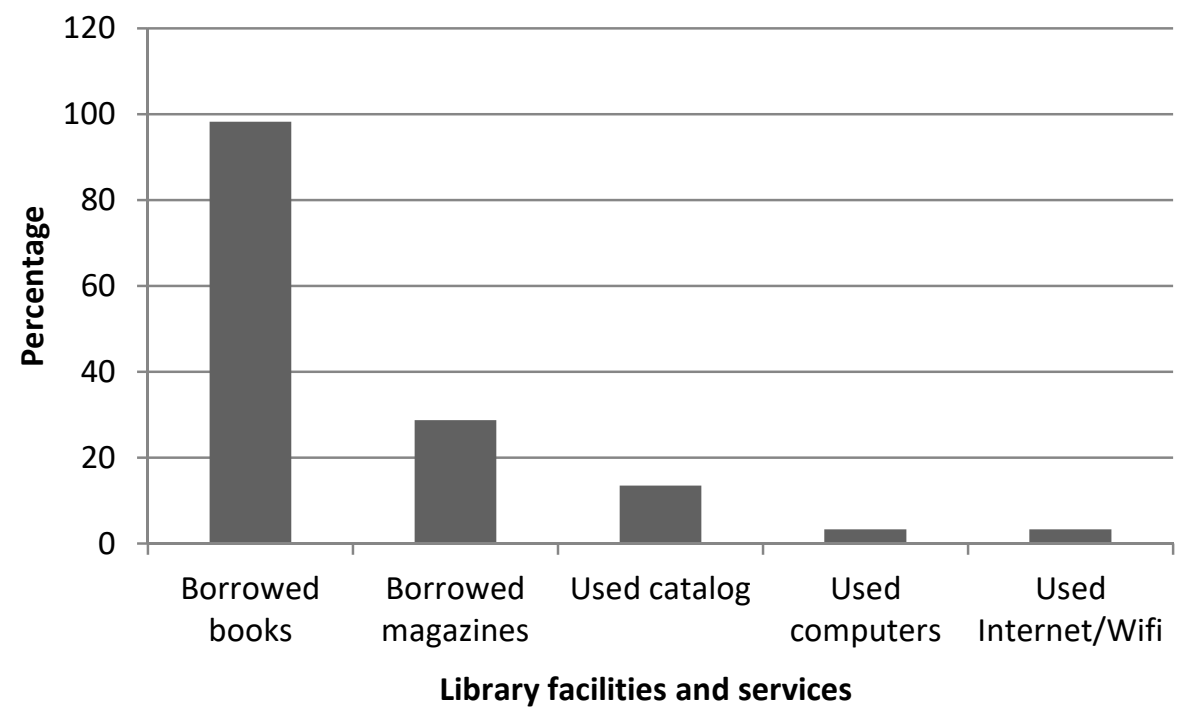

Figure 04. Use of school library facilities and services

\section{Use of Information Sources}

The participants were asked to state whether they perceived the need to read additional material to complement classroom notes. It was noteworthy that majority of the respondents $(94.91 \%)$ felt that they needed to refer other material. Further, the students were asked to indicate the types of information sources they used other than the school library. Figure 5 demonstrates the findings.

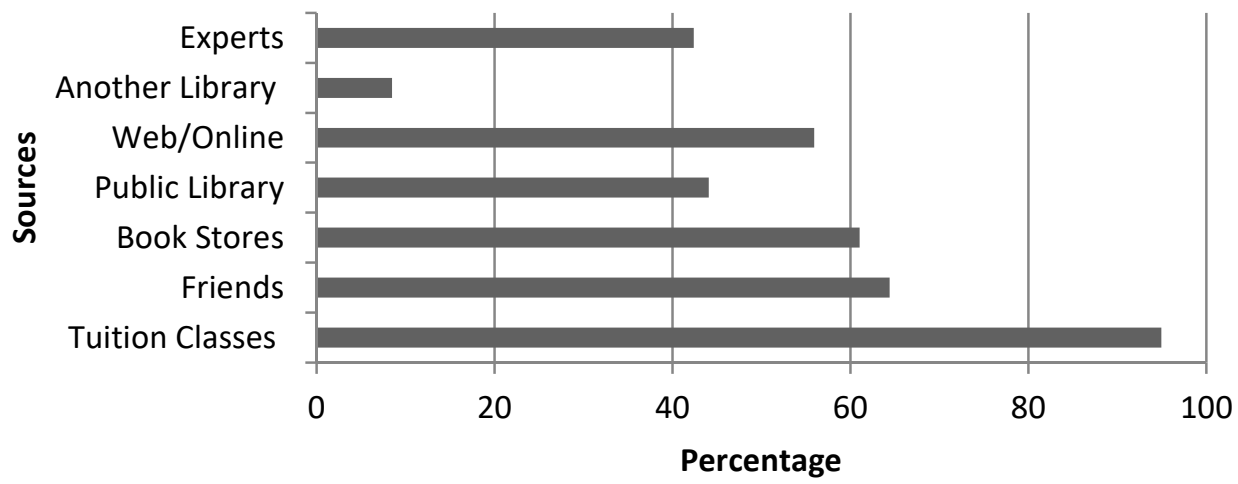

Figure 05. Use of information sources 
According to the results (Figure 5) it could be observed that most of the respondents (94.91\%) had obtained subject-related material from their tuition classes corroborating the findings of Wijetunge and Gunasekera (2015). There appears to be a trend in relying on tuition classes to gain additional reference material by students during their GCE A/L education. A substantial number of students $(64.41 \%)$ had borrowed relevant material from friends and relatives, while $61.02 \%$ of them had purchased material from book stores. More than half of the respondents $(55.93 \%)$ had utilized online material and $44.07 \%$ of them had used the public library. Furthermore, $42.37 \%$ of the respondents had inquired from experts when they needed information to help with their studies.

\section{Use of Email and Social Media}

In this digital era, email and social media are highly popular communication channels embraced by people all over the globe. Social media have captured the attention of millions of users and having accounts in one or more social media platforms is one of the highly popular and rapidly advancing activities on the Internet. Inevitably, all the respondents verified that they had email accounts and almost all the respondents (96.61\%) except a very few confirmed that they used social media.

Figure 6 presents the types of social media accounts maintained by the respondents.

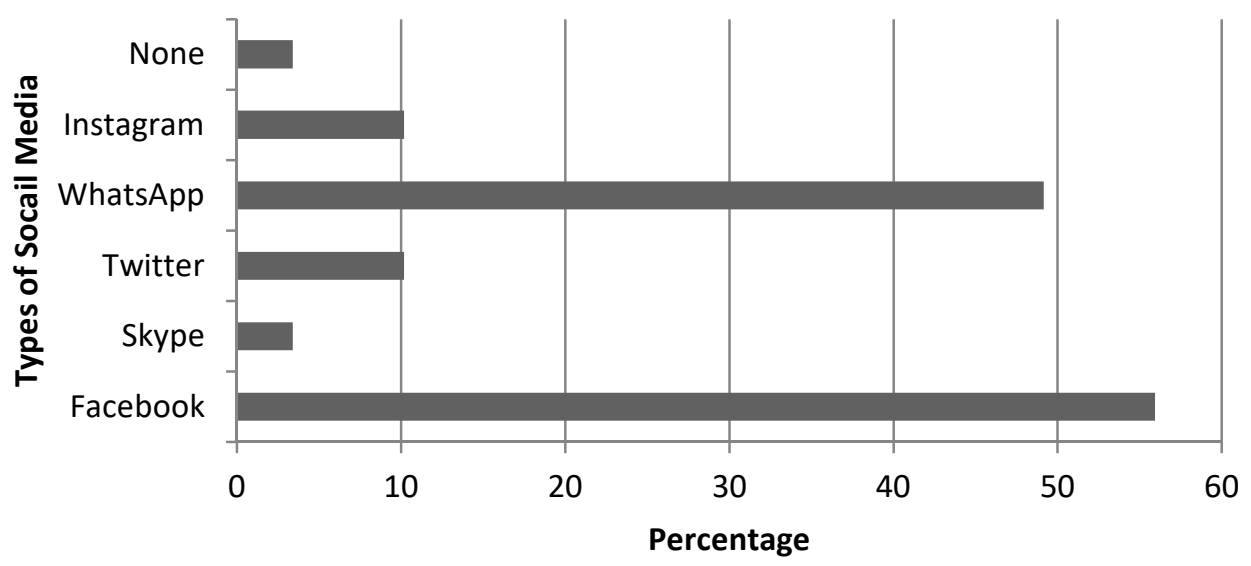

Figure 06. Types of social media used by respondents 
It was revealed that more than half of the respondents (55.93\%) had personal accounts on Facebook while some of them had accounts in Twitter (10.17\%) and Instagram (10.17\%). In addition, it was revealed that $49.15 \%$ of the respondents used WhatsApp (Figure 6). Yet, contrary to normal expectations, few students (3.39\%) reported that they did not have personal accounts in any social media.

A high percentage (93.22\%) of students confirmed that they were willing to communicate with the library using email while a considerable number of them $(71.19 \%)$ preferred to communicate with the library via social media. Yet, some students $(28.81 \%)$ were not interested in communicating with the Library through social media. The reason may be attributed to the fact that librarians are viewed as authorized officers in the university community and students may hesitate to consider librarians as "friends" in social media platforms.

\section{Conclusion and Recommendations}

This study shed light on the different perspectives of university new entrants with regard to their use of school library.It was evident through the findings that almost all the respondents had prior experience in using the school library and most of them had visited the library once a week. Regarding library facilities and services, majority of the students had borrowed books while some of them had borrowed magazines as well.According to the results only several students had used the library catalog. Also, a high percentage of students had not used computers in the library and most of them had no access to Internet/Wi-Fi in the library. Most of the students mentioned that they had highly depended on material provided by tuition classes as the major information source other than the school library to gain subject-related information. All the respondents verified that they owned an email account while most of them had social media accounts as well. A substantial number of respondents indicated that they preferred to communicate with the library via digital media (email and social media).

According to the results most of the new entrants had not used library catalogs before entering university. Thus, it is suggested that more focus 
should be given to include instruction and hands on training on OPAC (Online Public Access Catalog) use when designing library orientation programs for new students. It was revealed that majority of students had not used computers and internet in the school library which demonstrate that they may be less familiar in using computers and internet for scholarly purposes. It is advisable to pay more attention to incorporate concepts such as e-resources, internet searching and computer based library services into library instruction programs with more hands on sessions.

Results indicated that majority of students maintained email accounts as well as social media accounts, which exhibits the inclination towards technology of the new entrants who are digital natives. Furthermore, more than half of the respondents owned personal accounts on Facebook. Most of the respondents preferred to communicate with the library using email and social media. Yet, there were some students who were not willing to use social media for communications with the library. In the light of the findings, it is recommended that students should be educated about the benefits of the effective use of social media in libraries. Also, librarians should take innovative measures to use social media as interactive platforms to obtain user feedback, provide updates about new arrivals, events and library services, facilitate interactive, personalized user services etc. Facebook was revealed to be the most popular social media channel among the students. Thus, the library Facebook page could be innovatively integrated with other channels to render an added value to the user. For instance, the library Facebook page can be embedded with catalog search boxes, mash-ups as well as links to related YouTube videos which will enable students to interact with the library in the digital context.

Furthermore, librarians could assist students via e-mail reference services to bridge the gap between librarian and the information seeker (Mashroofa, 2012). Also, it is important that the library web page is frequently updated. Furthermore, Links to "ask a librarian", databases subscribed by the library and OPAC can be provided via the library web page.

Findings of the study can be applied as a baseline indicator when planning and designing library orientation programs and instruction programs for new 
entrants. More focus should be laid on areas such as OPAC use and computer based library services. Also, practical sessions could be conducted to educate students on database searching including accessing e-journals and internet searching for academic information. Moreover, this study will open avenues for other researchers to conduct studies in various contexts regarding prior library experiences of university freshman in diverse disciplines which is an area that have received less attention in library literature. Librarians should take into consideration the prior school library use of undergraduates and incorporate innovative strategies using emanating technologies such as social media to render quality services to undergraduates who are the main user community of the university library. Understanding prior library experience of university new comers is important for librarians to take effective measures to satisfy the information needs of the tech-savvy young users in their preferred environment breaking the limits of traditional library walls.

\section{References}

Alade, V.A., Iyoro, A.O. \& Amusa, O.I. (2014) Library use characteristics of undergraduates in Nigeria University of Science and Technology. Journal of Library \& Information Science, 4(1), 15-27. Retrieved from http://irjlis.com/wp-content/uploads/2014/06/2-IR186 .pdf

Benard, R. \& Dulle, F. W. (2014). Assessment of access and use of school library information resources by secondary schools students in Morogoro municipality, Tanzania. Library Philosophy and Practice (e-journal), 1107. Retrieved from: http://digitalcommons.unl.edu/ libphilprac/1107

Bransford, J. D., Brown, A. L., \& Cocking, R. R. (2000). How people learn (Vol. 11). Washington, DC: National academy press.

Fayose, P.O. (1995). School Library Resources Center for Educational excellence. Ibadan: Federal Ministry of Education p.13.

Fakomogbon, M.A., Bada,A.A., Omiola, M.A., \& Awoyemi, S. O. (2012). Assessment of school library resources in public secondary schools in Ilorin Metropolis. Interdisciplinary Journal of Contemporary Research in 
Business, 3(10), 486-492. Retrieved from: https://journal-archieves15. webs.com/486-492.pdf

Gunasekera, C. (2018). Exploring First Year Undergraduate Students' Information Literacy Skills: Experience at the Faculty of Management, University of Peradeniya, Sri Lanka. SRELS Journal of Information Management, 55(6), 309-314.

Hartmann, E. (2001). Understandings of information literacy: the perceptions of first year undergraduate students at the University of Ballarat. Australian Academic \& Research Libraries, 32(2), 110-122.

Kassim, N. A. (2017). Evaluating users' satisfaction on academic library performance. Malaysian Journal of Library \& Information Science, 14(2), 101-115. Retrieved from: https://jice.um.edu.my/ index.php/MJLIS/article/ view/6960

Kumara, A.D.B. (2014). Use of Information and Communication Technologies (ICTs) by university freshmen: with special reference to the University of Moratuwa. Journal of the University Librarians Association of Sri Lanka, 18(2), 26-40. Retrieved from: https://jula.sljol.info/article s/10.4038/jula.v18i2.7864/galley/5199/ down load/

Mashroofa, M.M. (2012). Requirements of net generation towards university libraries in Sri Lanka. Journal of the University Association of Sri Lanka, 16(2), 101-116. http://doi.org/10.4038/jula.v16i2.5202

Ukpebor, C. O. \& Emojorho, D. (2012). Information literacy skills: a survey of the transition of students from secondary to university education in Edo State, Nigeria. Library Philosophy \& Practice (e-journal), 824. Retrieved from: https://digitalcommons.unl.edu/libph ilprac/824/.

Whitmire, E. (2001). The relationship between undergraduates' background characteristics and college experiences and their academic library use. College \& Research Libraries, 62(6), 528-540. https://doi.org/ $10.5860 /$ crl.62.6.528 
Wijetunge, P. (2018). Uncertainty Encountered by the Humanities and Social Science Undergraduates in their Information Seeking Behaviour.. In W.J. Jeyaraj, S. Santharooban \& M. N. Ravikumar. (Eds.), Proceedings of the International symposium on emerging trends in education and library and information science (LibSym 2018) (pp 7-14). Eastern University, Sri Lanka.

Wijetunge, P. \& Gunasekera, C. (2015). Prior experiences of the new entrants in using the school library: with special reference to Management students, University of Peradeniya. Proceedings of the International Conference on Library and Information Science(ICLIS).79-85. Retrieved from: http://archive.cmb.ac.lk:8080/research/bitstream/70130/4111/1/iclis _2 015_8.pdf 